\title{
Heritability of Terbacil Herbicide Tolerance in Strawberry
}

\author{
C.A. Weber ${ }^{1}$ \\ Department of Horticultural Sciences, New York State Agricultural Experiment \\ Station, Cornell University, Geneva, NY 14456
}

Additional index words. Fragaria $\times$ ananassa, combining ability, herbicide damage, Sinbar

\begin{abstract}
A partial diallel design was used to investigate the inheritance of tolerance to terbacil herbicide in cultivated strawberry, Fragaria $\times$ ananassa Duch. Two tolerant cultivars, 'Honeoye' and 'Earliglow', two moderately tolerant cultivars, 'Lester' and 'Allstar', and two susceptible cultivars, 'Red Chief' and 'Guardian' were used as parents to create populations that segregated for tolerance to the herbicide. Tolerance rankings of the populations closely coincided with expected rankings based on the published tolerance levels of parental cultivars. 'Honeoye' and 'Earliglow' derived populations had the highest average tolerance ratings, while 'Guardian' derived populations had the lowest tolerance ratings. Heritability was estimated at $h^{2}=0.50$, indicating that significant progress in increasing the tolerance of new cultivars to terbacil can be achieved through traditional recurrent selection procedures. General and specific combining abilities suggest that the tolerant cultivars in this study may be fixed in their tolerance and that increased mean tolerance will be most apparent in progenies combining tolerant and susceptible cultivars. As such, a broader pool of germplasm may be needed to develop cultivars that are more tolerant than those in this study. Chemical names: terbacil (3-tert-butyl-5-chloro-6-methyluracil)
\end{abstract}

Weed control in matted row strawberry production continues to be the most pressing pest control problem in this system. Newly planted strawberries in the matted row system are most susceptible to weed competition during the period following planting. Yield losses of up to $65 \%$ have been documented when early season weed competition was not controlled (Pritts and Kelley, 2001). Weed control during this period is especially critical for the long-term viability of new plantings and is difficult because few herbicides with a limited residual activity are available for establishment year weed control (Pritts and Kelley, 2001).

Terbacil(3-tert-butyl-5-chloro-6-methyluracil) is an effective herbicide that is labeled for control of many annual and some perennial weeds during the establishment season of matted row strawberry plantings. It has good residual activity, low soil mobility and a caution registration label (EPAReg. No. 352-317) (Beste et al., 1983). Terbacil is applied in field conditions as a wettable powder over the top of the planting. If leaves are present, irrigation can be applied to remove the herbicide from the leaf surface to avoid leaf damage (Polter et al., 2004a, 2004b).

Terbacil is a photosynthesis inhibitor and, as such, is more toxic to seedlings due to their lack of carbohydrate reserves (Ashton and Crafts, 1973), thus providing effective early season weed control. However, tolerance to terbacil is highly variable among strawberry cultivars (Ahrens, 1982; Lindstrom and Swartz, 1987; Masiunas and Weller, 1986; Weller, 1984). Lindstrom and Swartz (1987) observed a

Received for publication 13 July 2004. Accepted for publication 4 Oct. 2004. This research was supported in part by a grant from the New York State Berry Growers Association.

${ }^{1}$ To whom reprint requests should be addressed. Email address: caw34@nysaes.cornell.edu. threefold difference in tolerance to terbacil after renovation among 22 strawberry genotypes. On a scale of 0 to 9 ( 9 being no injury), 'Earliglow' and 'Honeoye' rated as the most tolerant at 6.8 and 6.0, respectively after renovation (no leaves) and among the most tolerant at 5.0 for both without renovation. Redchief' and 'Guardian'were rated the most susceptible, especially when leaves were present during application (2.4 and 1.8, respectively). Most cultivars were more sensitive when the herbicide was applied on unrenovated plants (with leaves attached). Polter etal. $(2004,2005)$ showed that overhead irrigation to rinse the herbicide from the leaf surface greatly reduced strawberry plant injury in greenhouse and field studies. Masiunas and Weller (1986) found that tolerance was related to vigor of the transplants but that early season weed control could be successful using low rates of terbacil without serious plant injury if the plants were still dormant when it was applied.

The resistance to terbacil in strawberry has been attributed in part to the restricted translocation to the site of action in the mesophyll chloroplasts (Genez and Monaco, 1983b). Further, tolerance may be attributed somewhat to metabolism of the herbicide but no difference in rates of metabolism were found between a susceptible and tolerant cultivars (Genez and Monaco, 1983a). Indications are that anatomical features in the roots and/or vascular system and reduced translocation may account for the variability in tolerance (Genez and Monaco, 1983a, 1983b).

The range of tolerance to terbacil observed in strawberry cultivars indicates a large level of available genetic diversity that could be utilized for improving tolerance through breeding. However, genetic studies to investigate the heritability of tolerance or possible genetic control of this trait are lacking. Additionally, an assay for seedling populations for efficient selection for tolerance in breeding populations is needed.

The objective of this study was to evaluate populations of strawberry seedlings for tolerance to terbacil using a partial diallel design with six parental strawberry cultivars using a greenhouse seedling screening procedure. Heritability was calculated based on additive and non-additive variances determined through specific (SCA) and general combining ability (GCA) analyses.

\section{Materials and Methods}

A partial diallel design was used for calculation of combining abilities and a heritability estimate of tolerance to terbacil herbicide following the method of Griffing (1956a, 1956b) where $F_{1} s$ and parental self pollinations are included but not reciprocal crosses. The six parental cultivars included two tolerant cultivars, 'Earliglow and 'Honeoye', two intermediate in tolerance, 'Allstar' and 'Lester', and two susceptible cultivars, 'Red Chief' and 'Guardian' as ranked by Lindstrom and Swartz (1987)

Hybridizations were made in the greenhouse to develop a total of 21 populations (15 $\mathrm{F}_{1} \mathrm{~s}$ and six parental self-pollinations). Unopened flowers were emasculated by hand and pollinated 1 to $2 \mathrm{~d}$ later when the stigmas were receptive. Anthers were collected from the same flowers, allowed to dry overnight and stored in glass bottles in a refrigerator at $4{ }^{\circ} \mathrm{C}$ with the dehisced pollen for use in pollinations.

Mature fruit were collected and the seed extracted and air-dried. Seeds were scarified in concentrated sulfuric acid for $5 \mathrm{~min}$, rinsed under tap water for $5 \mathrm{~min}$, and stratified in moist vermiculite at $4{ }^{\circ} \mathrm{C}$ for 8 weeks. After stratification, seeds were sown in a soilless medium containing 1.2 peat : 1 vermiculite supplemented with $10 \mathrm{~N}-5 \mathrm{P}-10 \mathrm{~K}$ fertilizer and placed in a greenhouse under supplemental light to provide a 14-h photoperiod. Temperatures were maintained at 29 and 21 ${ }^{\circ} \mathrm{C}$ day and night, respectively. Excess seed from each population was planted to ensure sufficient numbers of seedlings were available for testing at a similar stage of growth. Seedlings were picked at the two single-leaflet stage and planted in two replicates of 32 plants in $5.1 \times 5.1 \times 10.2 \mathrm{~cm}$ cell packs for each of the 21 seedling populations. Space restrictions in the greenhouse necessitated a completely randomized design for the experiment.

Preliminary testing on strawberry seedlings with levels of terbacil ranging from 0.125 to $1.0 \mathrm{mg} / \mathrm{seedling}$ cell showed $0.25 \mathrm{mg} /$ plant was an effective concentration for inducing symptoms and identifying tolerant genotypes (unpublished data). After the seedlings reached four to five true leaves, they were treated with $0.25 \mathrm{mg}$ terbacil wettable powder using a solution of $1 \mathrm{~g} \cdot \mathrm{L}^{-1}(80 \%$ active ingredient), applied on the soil surface near the base of the crown in each cell with a pipettor. Symptoms appeared within 2 weeks, including interveinal chlorosis, leaf curling and browning, reduced 
Table 1. Mean progeny scores for damage from the herbicide terbacil on strawberry populations treated with $0.25 \mathrm{mg}$ per plant in a greenhouse screen. A rating scale of 1 to 10 was used with 1 = dead; 3 = severe leaf necrosis but with living crown; 5=moderate symptoms with some leaf edge browning and mild chlorosis; $7=$ healthy but displaying mild chlorosis but no browning; $10=$ healthy with no symptoms.

\begin{tabular}{lcc}
\hline Cultivar & $\begin{array}{c}\text { Mean } \\
\text { damage } \\
\text { rating }^{z}\end{array}$ & $\begin{array}{c}\text { Reported } \\
\text { tolerance }^{y}\end{array}$ \\
\hline Honeoye & $5.3 \mathrm{a}$ & High \\
Earliglow & $5.1 \mathrm{a}$ & High \\
Lester & $4.8 \mathrm{~b}$ & Moderate \\
Allstar & $4.7 \mathrm{~b}$ & Moderate \\
Red Chief & $4.6 \mathrm{~b}$ & Low/moderate \\
Guardian & $4.1 \mathrm{c}$ & Low \\
LSD $_{0.05}$ & 0.28 & \\
\hline
\end{tabular}

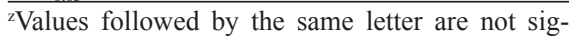
nificantly different at $P \leq 0.05$ according to least significant difference (LSD) test.

${ }^{\mathrm{y}}$ Lindstrom and Swartz, 1987.

vigor, and plant death in some cases. After 4 weeks, the plants were evaluated for symptoms of herbicide damage on a scale of 1 to $10(1=$ dead; 3 = severe leaf necrosis but with living crown; 5 = moderate symptoms with some leaf edge browning and mild chlorosis; $7=$ healthy but displaying mild chlorosis but no browning; $10=$ healthy with no symptoms). An analysis of variance was used to test for treatment significance. The data was further analyzed using the method of Griffing (1956a, $1956 b)$ to calculate narrow sense heritability, general and specific combining abilities, and estimated additive and dominance plus interaction effects.

\section{Results}

All populations showed substantial symptoms of herbicide toxicity including chlorosis, leaf browning and plant death. Rankings of the cultivars, based on the ratings of the populations for which each was a parent, closely resembled previously published rankings (Lindstrom and Swartz, 1987) (Table 1). Populations with 'Honeoye' or 'Earliglow' as a parent had the highest mean tolerance ratings. Populations with 'Guardian' as a parent showed the most herbicide susceptibility while populations with 'Allstar', 'Lester' or 'Red Chief' as parents showed an intermediate response to the herbicide treatment (Table 1).

A heritability of $\mathrm{h}^{2}=0.50$ was calculated for tolerance based on the symptom ratings. The variance components for GCA and SCA were similar(Table 2) but with higher GCA variance, thus indicating a greater role for additive gene action. The SCA variance component was also significant indicating a large dominance plus interaction gene effect. GCA was positive for 'Honeoye', 'Earliglow' and 'Allstar' (Table 3) and negative for 'Red Chief', 'Lester' and 'Guardian' (Table 3). SCA was most strongly positive for the population of 'Guardian' $x$ 'Earliglow' and most strongly negative for 'Allstar' × 'Guardian' (Table 4). There were seven positive and eight negative SCAs among the $15 \mathrm{~F}_{1}$ populations with an average value of 0.33 and -0.80 , respectively (Table 4$)$.

Table 2. Mean square, F ratio and $P$ value for general (GCA) and specific (SCA) combining ability for tolerance to terbacil in strawberry progenies.

\begin{tabular}{lrccc}
\hline Source & df & Mean square & F ratio & $P$ value \\
\hline GCA & 5 & 1.07 & 4.84 & $<0.01$ \\
SCA & 15 & 0.84 & 3.83 & $<0.01$ \\
Error & 21 & 0.22 & & \\
\hline
\end{tabular}

\section{Discussion}

Numerous researchers have documented variability in tolerance to terbacil herbicide among strawberry cultivars (Ahrens, 1982; Lindstrom and Swartz, 1987; Masiunas and Weller, 1986; Weller, 1984), thus the observed segregation for tolerance within these strawberry populations was expected. Numerous physiological factors have been implicated in tolerance including restricted translocation (Genez and Monaco, 1983b), metabolic detoxification (Genez and Monaco, 1983a) and differences in plant vigor (Masiunas and Weller, 1986). Multiple genes likely influence these components of tolerance and account for the quantitative segregation expressed in progeny populations.

Previous studies on tolerance to terbacil in strawberry have been completed on mature, clonally propagated crowns rather than seedling populations (Polter etal., 2004, 2005; Lindstrom and Swartz, 1987; Masiunas and Weller, 1986; Genez and Monaco, 1983a, 1983b). As a photosynthetic inhibitor, terbacil is expected to be more active in seedlings and rapidly growing plants (Ashton and Crafts, 1973). Thus seedling tests may not accurately measure future field results. However, ranking of parents in this study based on the performance of their offspring closely coincided with their field rankings from Lindstrom and Swartz (1987) suggesting that seedling performance may be a good indicator of field performance.

Lindstrom and Swartz (1987) found that most cultivars were moderately tolerant with the notable exception of 'Guardian', which is very susceptible to terbacil. 'Earliglow' and 'Honeoye' were the most tolerant in their study, especially following renovation. This agrees with the assessment of Masiunas and Weller (1986), who suggested that vigorous

Table 3. General combining ability (GCA) for tolerance to terbacil for six strawberry cultivars.

\begin{tabular}{lr}
\hline Cultivar & GCA \\
\hline Honeoye & 0.43 \\
Earliglow & 0.23 \\
Allstar & 0.11 \\
Lester & -0.02 \\
Red Chief & -0.12 \\
Guardian & -0.63 \\
\hline
\end{tabular}

cultivars are more tolerant. Observations in demonstration plots at Cornell University's New York State Agricultural Experiment Station in Geneva, N.Y., have shown that 'Earliglow' and 'Honeoye' are vigorous and renovate well, which may account for some of their tolerance level.

Genez and Monaco (1983b) found that tolerance in strawberry was attributed, in part, to restricted translocation within the plant and that metabolism of terbacil did not differ between tolerant and susceptible strawberry cultivars (Genez and Monaco, 1983a). Thus less vigorous varieties may still possess and transmit alleles for improved tolerance due to reduced transport. When combined with a vigorous, tolerant cultivar the progeny could show marked improvement. The relatively high heritability that was calculated, $\mathrm{h}^{2}=0.50$, may reflect these combinations. However, a relatively high level of dominance plus interaction effect is also indicated by the nearly equal GCA and SCA variance components (Table 2 ). Thus some cultivars may be nearly fixed for tolerance alleles and improvement would not be expected in their combined progenies.

This fixed genetic state would be indicated by low or negative SCAvalues when combined with other tolerant cultivars. The SCA for the 'Honeoye' $\times$ Earliglow' (tolerant $\times$ tolerant) population supports this, being basically neutral at $\mathrm{SCA}=0.02$, as does the negative SCA values for most of the 'Allstar' populations (Table 4). The low and negative SCA values observed in ten of the progenies suggests that combining the tolerant cultivars in this study will yield little improvement in their progeny. The generally positive SCA values when the tolerant cultivars 'Earliglow' and 'Honeoye' were combined with less tolerant cultivars suggests that with susceptible cultivars, means higher than the mid parent value can be realized in progeny populations.

Additionally, the relatively small germplasm pool represented here may not include the full range of tolerance available in strawberry. Progeny from the moderately tolerant cultivars have variable SCA values, both positive and negative. A similar background in genes for tolerance or susceptibility may explain this variability. 'Allstar' is closely related to 'Guardian' and 'Red Chief', being a half-sibling to both (Galletta, 1997). Addition-

Table 4. Specific combining ability (SCA) for tolerance to terbacil for 15 strawberry progeny. Means from the parental self pollinations are presented in parentheses in each column.

\begin{tabular}{|c|c|c|c|c|c|c|}
\hline \multirow{2}{*}{$\begin{array}{l}\text { Female } \\
\text { parent }\end{array}$} & \multicolumn{6}{|c|}{ Male parent } \\
\hline & Allstar & Red Chief & Guardian & Lester & Honeoye & Earliglow \\
\hline Allstar & $(6.68)$ & 0.22 & -1.47 & -0.29 & -0.59 & -1.04 \\
\hline Red Chief & & $(5.50)$ & -1.06 & -1.46 & 0.62 & -0.08 \\
\hline Guardian & & & $(4.53)$ & 0.34 & -0.37 & 0.67 \\
\hline Lester & & & & $(5.33)$ & 0.42 & 0.00 \\
\hline Honeoye & & & & & $(5.67)$ & 0.02 \\
\hline Earliglow & & & & & & $(5.53)$ \\
\hline
\end{tabular}


ally, 'Guardian' and 'Red Chief' are siblings (Galletta, 1997). Improvement (positive SCA) would be seen in populations where tolerance genes compliment each other in an additive fashion but not in inbred populations. When the genetic background is similar and heterozygous for tolerance loci, segregation would be expected but a lower population mean (negative SCA) could be expected because no additional alleles for tolerance would be added to the mix. Thus tolerance levels greater than the most tolerant cultivars in this study may only be possible by utilizing a broader germplasm pool with alleles for tolerance not represented here.

It is also possible that variable sensitivity to the herbicide in the chloroplasts (i.e., a maternal effect) is responsible for some of the tolerance differences observed in strawberry cultivars. Boydston and Al Khatib (1992) found resistance to terbacil and the related compound bromacil (5-bromo-3-sec-butyl6-methyluracil) to be at the chloroplast level in Powel amaranth (Amaranthus powellii S. Wats.). Radosevich et al. (1979) found a similar resistance mechanism in common groundsel (Senecio vulgaris L.). However, no differences in chloroplast affinity to terbacil were found in alfalfa (Medicago sativa L.) (Anderson et al., 1995) or to the related compound lenacil (3-cyclohexyl-1,5,6,7-tetrahydrocyclopentapyrimidine-2,4(3H)-dione) in sugar beet (Beta vulgaris L.) (Dominguez et al., 1992).

Variable chloroplast affinity can not be ruled out in this study because the most tolerant cultivars, 'Honeoye' and 'Earliglow', were not used as female parents except in self-pollinations and in the cross between each other (Table 4). However, the most positive SCA values in this study were found when these two cultivars were used as male parents with the most susceptible parents (Table 4). This indicates that a maternal effect, if present, is relatively minor and that a dominance effect of nuclear genes is important in conferring tolerance. These genes may be involved in transport mechanisms and/or vascular system anatomy or contribute to increased vigor.

In conclusion, the positive GCA for 'Earliglow', 'Honeoye' and 'Allstar' indicates that improvement can be made through breeding, especially in susceptible germplasm. Combining susceptible cultivars with tolerant cultivars will substantially increase the mean tolerance of new populations. Hybridizations between susceptible and/or low vigor cultivars with tolerant cultivars, which may be fixed for tolerance alleles or combine alleles conferring increased vigor with moderate tolerance, could yield progeny with tolerance levels significantly better than the mid parent. However, increasing the level of tolerance to a point higher than the most tolerant cultivars in this study will most likely require a broader germplasm pool from which to locate favorable alleles at additional genetic loci contributing to tolerance.

\section{Literature Cited}

Ahrens, J.F. 1982. Napropamide and terbacil for newly planted strawberries. Adv. Strawberry Prod. 1:22-26.

Anderson, M.P., C. Bensch, J.F. Stritzke, and J.L. Caddel. 1995. Uptake, translocation, and metabolism in alfalfa (Medicago sativa) selected for enhanced tolerance to terbacil. Weed Sci. 43:365-369.

Ashton, F.M. and A.S. Crafts. 1973. Mode of action of herbicides. Wiley, New York.

Beste, C.E., N.E. Humburg, H.M. Kempen, R.O. Radke, J.D. Riggleman, J.F. Stritzke, and G.R. Miller. 1983. Weed Science Society of America handbook. Weed Sci. Soc. Amer., Champaign, Ill.

Boydston, R.A. and K. Al-Khatib. 1992. Terbacil and bromacil cross-resistance in Powell amaranth (Amaranthus powellii). Weed Sci. 40:513-516.

Dominguez, C., E. Romera, J.M. Perez de la Lastra, and R. de Prado. 1992. Effect of phenmed- ipham and lenacil on three sugarbeet varieties, p. 327-331. Proc. 1992 Conf. Spanish Weed Sci. Soc.

Galletta, G. 1997. Strawberry, p. 669-737. In: The Brooks and Olmo register of fruit and nut varieties. 3rd ed. ASHS Press, Alexandria, Va.

Genez, A.L. and T.J. Monaco. 1983a. Metabolism of terbacil in strawberry (Fragaria $\times$ ananassa) and goldenrod (Solidago fistulosa). Weed Sci. 31:221-225.

Genez, A. L. and T.J. Monaco. 1983b. Uptake and translocation of terbacil in strawberry (Fragaria $\times$ ananassa) and goldenrod (Solidago fistulosa). Weed Sci. 31:56-62.

Griffing, B. 1956a. A generalised treatment of the use of diallel crosses in quantitative inheritance. Heredity 10:31-50.

Griffing, B. 1956b. Concept of general and specific combining ability in relation to diallel crossing systems. Austral. J. Biol. Sci. 9:463-493.

Lindstrom, J.T. and H. J. Swartz. 1987. Strawberry genotype responses to terbacil. Adv. Strawberry Prod. 6:44-46.

Masiunas, J.B. and S.C. Weller. 1986. Strawberry cultivar response to postplant applications of terbacil. HortScience 21:1147-1149.

Polter, S.B., D. Doohan, and J.C. Scheerens. 2004. Tolerance of greenhouse-grown strawberries to terbacil as influenced by cultivar, plant growth stage, application rate, application site and simulated post-application irrigation. HortTechnology 14(2):223-229.

Polter, S.B., D. Doohan, and J.C. Scheerens. 2005. The effect of irrigation on terbacil tolerance in field-grown strawberries. HortTechnology (in press).

Pritts, M.P. and M. Kelly. 2001. Early season weed competition reduces yield of newly planted matted row strawberries. HortScience 36:729-731.

Radosevich, S.R., K.E. Steinback, and C.J. Arntzen. 1979. Effect of photosystem II inhibitors on thylakoid membranes of two common groundsel (Senecio vulgaris) biotypes. Weed Sci. 27:216-218.

Weller, S.C. 1984. Evaluation of postplant applications of terbacil and napropamide to strawberry plants. Adv. Strawberry Prod. 3:15-19. 